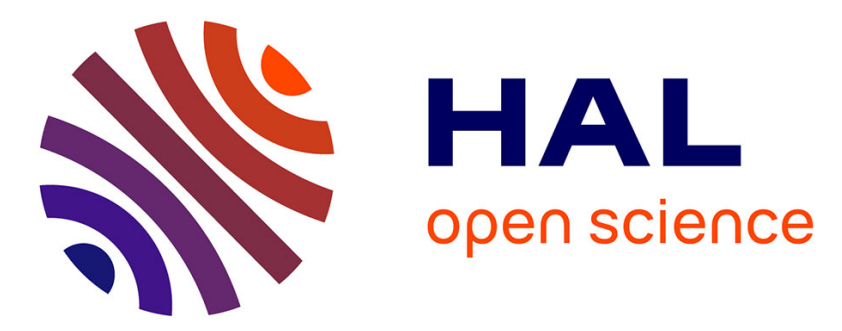

\title{
Conformational Polymorphism: The Missing Phase of 1,1,2,2-Tetrachloroethane (Cl2HC-CHCl2)
}

Philippe Négrier, María Barrio, Josep Ll Tamarit, Denise Mondieig, M. J. Zuriaga, S. C. Perez

\section{To cite this version:}

Philippe Négrier, María Barrio, Josep Ll Tamarit, Denise Mondieig, M. J. Zuriaga, et al.. Conformational Polymorphism: The Missing Phase of 1,1,2,2-Tetrachloroethane (Cl2HC-CHCl2). Crystal Growth \& Design, 2013, 13 (5), pp.2143-2148. 10.1021/cg400235b . hal-00834309

\section{HAL Id: hal-00834309 https://hal.science/hal-00834309}

Submitted on 8 Jan 2018

HAL is a multi-disciplinary open access archive for the deposit and dissemination of scientific research documents, whether they are published or not. The documents may come from teaching and research institutions in France or abroad, or from public or private research centers.
L'archive ouverte pluridisciplinaire HAL, est destinée au dépôt et à la diffusion de documents scientifiques de niveau recherche, publiés ou non, émanant des établissements d'enseignement et de recherche français ou étrangers, des laboratoires publics ou privés.

\section{다(1)(2)}

Distributed under a Creative Commons Attribution - ShareAlikel 4.0 International 


\title{
Conformational Polymorphism: The Missing Phase of 1,1,2,2- Tetrachloroethane $\left(\mathrm{Cl}_{2} \mathrm{HC}-\mathrm{CHCl}_{2}\right)$
}

\author{
Ph. Negrier, ${ }^{\dagger}$ M. Barrio, ${ }^{\ddagger}$ J. Ll. Tamarit, ${ }^{*}{ }^{\ddagger}$ D. Mondieig, ${ }^{\dagger}$ M. J. Zuriaga, ${ }^{\S}$ and S. C. Perez ${ }^{\S}$ \\ ${ }^{\dagger}$ Université Bordeaux, LOMA, UMR 5798, F 33400 Talence, France CNRS, LOMA, UMR 5798, F 33400 Talence, France \\ ${ }^{\ddagger}$ Grup de Caracterització de Materials, Departament de Física i Enginyeria Nuclear, ETSEIB, Diagonal 647, Universitat Politècnica de \\ Catalunya, 08028 Barcelona, Catalonia (Spain) \\ ${ }^{\S}$ Facultad de Matemática, Astronomía y Física, Universidad Nacional de Córdoba and IFEG CONICET, Ciudad Universitaria, \\ X5016LAE Córdoba, Argentina
}

\begin{abstract}
Halogenoethane derivatives are known to exhibit different polymorphs involving a different translational, orientational, and conformational order. The 1,1,2,2 tetrachloroethane $\left(\mathrm{Cl}_{2} \mathrm{HC}-\mathrm{CHCl}_{2}\right)$ exhibits a normal pressure orthorhombic phase $\beta$ (space group $P 2_{1} 2_{1} 2_{1}$ with $Z=8$ and $Z^{\prime}=2$ ), formed by molecules with one of the two gauche conformations. At high pressure, the stable polymorph is known to be monoclinic (space group $P 2_{1} / c$, with $Z=2$ and $Z^{\prime}=0.5$ ), phase $\alpha$, in which only the trans conformer appears. In this work, we demonstrate the existence of a normal pressure metastable polymorph, phase $\gamma$, for which the two gauche conformers show up in the asymmetric unit of a monoclinic (space group $P 2_{1} / c$ with $Z=8$ and $Z^{\prime}=2$ ) structure. The new phase $\gamma$ is obtained by recrystallization upon heating the glass obtained after quench of the melt. It displays shorter type II $\mathrm{Cl} \cdots \mathrm{Cl}$ contacts than the high pressure phase $\alpha$ due to attractive and directional interactions.
\end{abstract}

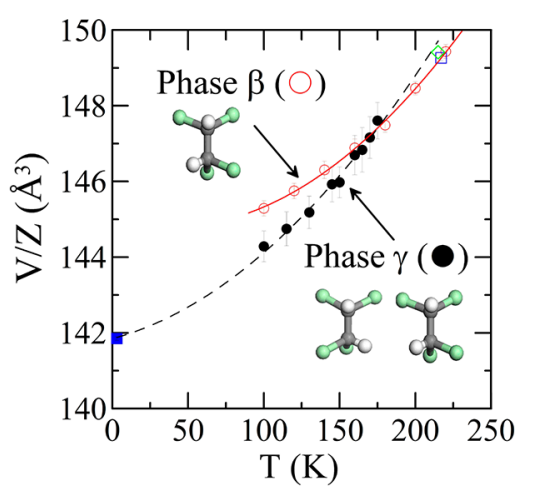

\section{INTRODUCTION}

Many organic compounds can crystallize in more than one crystal form, an ability which is known as polymorphism. ${ }^{1-4}$ Controlling the formation of different polymorphs for a compound is still a challenge in crystal engineering, and thus, many polymorphs are found serendipitiously. ${ }^{5-8}$ The different polymorphs have different crystal structures due to different crystal packing arrangements and/or different conforma tions. $^{8-15}$ For nonconformationally rigid molecules, as the case of $1,1,2,2$ tetrachloroethane $\left(\mathrm{Cl}_{2} \mathrm{HC}-\mathrm{CHCl}_{2}\right)$, molecules can be packed in alternative crystal structures due to the slight changes in the intermolecular interactions. These, in addition, are strongly dependent on the thermodynamic (temperature and pressure) conditions. The polymorphism of $1,1,2,2$ tetrachloroethane (1122TCE) has been recently revisited by Bujak et al. ${ }^{16,17}$ At normal pressure 1122TCE crystallizes on cooling at $231 \mathrm{~K}$ into an orthorhombic (space group $P 2_{1} 2_{1} 2_{1}$ ) structure with $Z=8$ and $Z^{\prime}=2$ ( $\beta$ phase), the two molecules of the asymmetric unit corresponding to $C_{2}$ symmetric gauche conformers (both gauche ${ }^{+}$). Although Kolesov ${ }^{18}$ postulated two normal pressure polymorphs enantiotropically related by a $\lambda$ type transition, only the $\beta$ phase has been demonstrated to appear at normal pressure in previous studies as well as in the more recent structural works. ${ }^{16}$ The measurements in the present work confirm these results. When the liquid phase of $1122 \mathrm{TCE}$ is pressurized, it crystallizes into a monoclinic (space group $\left.P 2_{1} / c\right)$ structure, with $Z=2$ and $Z^{\prime}=0.5$ ( $\alpha$ phase). In this phase, molecules appear in the trans (antiperiplanar) conformation. ${ }^{16}$ Two reasons seem to be in favor of such a conformation at high pressure. On one hand, trans conformer has a higher molecular symmetry $\left(C_{2 h}\right)$ than gauche $\left(C_{2}\right)$ and, on the other hand, the molecular volume of trans molecules is slightly smaller. Both features would support a more efficiently packed phase $\alpha$ which makes its physical appearance at high pressure. The early work of Brasch ${ }^{19}$ described the conformers appearing at normal and high pressure, as gauche and trans, respectively. The results obtained recently by Bujak et al. ${ }^{16}$ are consistent with those published by Brasch and with previous plentiful infrared and Raman spectroscopic studies at normal pressure. $^{20-25}$ These works confirm that liquid and vapor states consist of mixtures of trans and gauche molecules, the last one being the more stable isomer, although the energy difference between them is very small (less than ca. $1 \mathrm{kcal} \mathrm{mol}^{-1}$ ). ${ }^{20-25}$ It should be remembered that trans conformers are generally favored over the gauche in the vapor state of most substances because atoms in the latter have a higher steric strain due to being closer to each other. Nevertheless, for some compounds, as some halogenoethanes ${ }^{26-28}$ the opposite behavior (gauche being more stable) has been reported, an effect that has been called the "gauche effect". 29,30

Slow or fast cooling of the 1122TCE liquid always gave a crystal with the gauche conformer. ${ }^{24}$ In the original work of 
Brasch, ${ }^{19}$ single crystals of $1122 \mathrm{TCE}$ were obtained by pressurization at ambient temperature and by immersing the pressurized high pressure cell into liquid nitrogen, in both cases giving rise to the phase $\alpha$ structurally described by Bujak et al. ${ }^{16}$ When pressure is relaxed at low temperature, phase $\alpha$ transforms to phase $\beta$, which is also obtained by decreasing temperature at normal pressure, probing its stable character in such conditions.

In the present work, upon fast cooling the melt of $1122 \mathrm{TCE}$, no recrystallization was evidenced. On reheating the so obtained glass, a recrystallization of the metastable melt appears into a new polymorph, which upon heating again irreversibly transforms to the stable phase $\beta$. The structural characteristics of this new polymorph (phase $\gamma$ ) are described and compared to those previously found.

\section{MATERIALS AND METHODS}

Hydrogenated and deuterated 1122TCE compounds were purchased from Fluka and Aldrich chemical companies with purities of 98.0 and $99.5 \%$, respectively.

Differential Scanning Calorimetry. Differential scanning calori metric measurements were conducted by means of a Perkin Elmer DSC 7 apparatus equipped with a homemade low temperature device. Sample masses of about $25 \mathrm{mg}$, weighed with a balance sensitive to $0.01 \mathrm{mg}$, were hermetically sealed into high pressure stainless steel pans also from Perkin Elmer, and heating rates of $2 \mathrm{~K} \mathrm{~min}^{-1}$ were used. Temperature and enthalpy calibrations were performed with the standard indium.

X-ray Powder Diffraction. X ray powder diffraction patterns of hydrogenated 1122TCE were recorded by means of a horizontally mounted INEL cylindrical position sensitive detector (CPS120). Temperature was controlled by means of a liquid nitrogen 600 series cryosystem cooler from Oxford Cryosystems (temperature accuracy of $0.1 \mathrm{~K}$ ) working within the $100-300 \mathrm{~K}$ temperature range. The diffractometer was used in the Debye-Scherrer geometry (trans mission mode), enabling a simultaneous recording of the profile over a $2 \theta$ range between $4^{\circ}$ and $120^{\circ}$ (angular step of $0.029^{\circ}$ in $2 \theta$ ) with monochromatic $\mathrm{Cu} \mathrm{K}_{\alpha 1}$ radiation $(\lambda=1.54056 \AA)$ with asymmetric focusing incident beam curved quartz monochromator. External calibration was performed by using $\mathrm{Na}_{2} \mathrm{Ca}_{2} \mathrm{Al}_{2} \mathrm{~F}_{14}$ mixed with silver behenate as previously described. ${ }^{31,32}$

In order to diminish as much as possible preferred orientations, the sample was introduced in Lindemann capillaries $(0.2 \mathrm{~mm}$ diameter) which rotate along their longitudinal axes during data collection.

Acquisition times were at least $60 \mathrm{~min}$, and a stabilization time of at least $5 \mathrm{~min}$ at each temperature before data acquisition was selected. A long time acquisition pattern was obtained at $150 \mathrm{~K}$ and used for refinement purposes.

Neutron Powder Diffraction. Powder diffraction measurements on several grams of deuterated $1122 \mathrm{TCE}$ were conducted by means of the high resolution powder diffractometer SPODI at FMRII (Technische Universität Darmstadt, Germany), which was used within the standard configuration $\left(2 \theta_{\max }=155^{\circ}\right)$ and $\lambda=2.537 \AA^{33}$ Measurements at $3.5 \mathrm{~K}$ on the new polymorph were performed in order to analyze its metastable character at low temperature.

Nuclear Quadrupole Resonance (NQR). ${ }^{35} \mathrm{Cl} \mathrm{NQR}$ measure ments were done in deuterated 1122TCE using a Fourier transform pulse spectrometer with a Tecmag NMRkit II unit and a Macintosh based real time NMR station. The sample container was a glass cylinder of length $3 \mathrm{~cm}$ and diameter $1 \mathrm{~cm}$, closed under a vacuum.

The measurements were made upon the echo by the standard two pulse $\pi / 2-\tau-\pi$ sequence, and the line shapes were obtained by using spin-echo Fourier transform mapping spectroscopy. ${ }^{34}$ For phases $\beta$ and $\gamma$, the number of averages was $40, \pi / 2$ pulse length of $14 \mu \mathrm{s}$, and $\tau$ $=100 \mu \mathrm{s}$, while for the glassy phase the number of averages was 1000, $\pi / 2$ pulse length of $14 \mu \mathrm{s}$, and $\tau=70 \mu \mathrm{s}$. The temperature was controlled to within $0.1 \mathrm{~K}$ using a homemade cryogenic system with a Lakeshore temperature controller.

\section{RESULTS}

The new polymorph of 1122TCE was first found through calorimetric measurements. After quench of the liquid to the glassy state at ca. $120 \mathrm{~K}$, the glass phase was heated at 4 $\mathrm{K} \cdot \mathrm{min}^{-1}$ rate $\left(T_{\mathrm{g}} \approx 153 \mathrm{~K}\right)$ until the metastable liquid recrystallized into the new phase $\gamma$ at ca. $165 \mathrm{~K}\left(\Delta H^{\mathrm{liq} \rightarrow \gamma}=\right.$ $\left.-5.98 \mathrm{~kJ} \mathrm{~mol}^{-1}\right)$. Upon further heating, phase $\gamma$ exothermally and irreversibly transforms into phase $\beta$ at ca. $200 \mathrm{~K}\left(\Delta H^{\gamma \rightarrow \beta}=\right.$ $\left.-2.30 \mathrm{~kJ} \mathrm{~mol}^{-1}\right)$, which finally melts at $231.0 \mathrm{~K}\left(\Delta H^{\beta \rightarrow \text { liq }}=10.1\right.$ $\mathrm{kJ} \mathrm{mol}^{-1}$ ) (see Figure 1). The temperature and enthalpy change

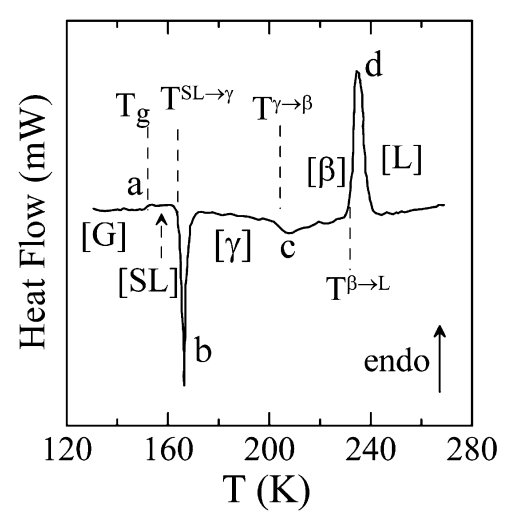

Figure 1. Differential scanning calorimetric curve recorded upon heating the glass obtained from the quench of the liquid. Calorimetric peaks: (a) glass transition at $T_{\mathrm{g}}$ from glass state to supercooled liquid, (b) recrystallization at $T^{\mathrm{SL} \rightarrow \gamma}$ of the supercooled metastable liquid (SL) into phase $\gamma,(\mathrm{c})$ irreversible transition at $T^{\gamma \rightarrow \beta}$ from metastable phase $\gamma$ to stable phase $\beta$, (d) melting of phase $\beta$ at $\mathrm{T}^{\beta \rightarrow \mathrm{L}}$.

of melting for phase $\beta$ perfectly agree with literature values. ${ }^{35}$ When the heating from the glass is limited, such that the phase $\beta$ is formed and the sample is cooled again, no thermal effect is observed down to the lowest temperature reached (ca. $100 \mathrm{~K}$ ). This experimental fact proves that phase $\beta$ is the stable polymorph at normal pressure (i.e., in equilibrium with the vapor phase).

$\mathrm{X}$ ray diffraction patterns of the phase $\gamma$ were obtained by repeating the same procedure used for calorimetric measure ments. In addition, the same phase $\gamma$ could be directly obtained when the liquid was cooled down to $100 \mathrm{~K}$ at a constant rate of about $5 \mathrm{~K} \mathrm{~min}^{-1}$. Patterns were collected on heating every $15 \mathrm{~K}$ from 100 to $160 \mathrm{~K}$ and every $5 \mathrm{~K}$ from $160 \mathrm{~K}$ till the irreversible transition to the phase $\beta$, which appears at ca. $180 \mathrm{~K}$.

In order to provide additional information for the structural determination, $\mathrm{NQR}$ experiments were conducted by using the same procedure to obtain the different phases. This technique provides a ${ }^{35} \mathrm{Cl} \mathrm{NQR}$ spectrum for which the number of resonant lines is proportional to the number of nonequivalent nuclei in the crystal, and the area under the NQR line is proportional to the number of resonant nuclei at that frequency. Thus, phase $\beta$ of 1122TCE must show eight lines (see Figure 2), since the asymmetric unit contains two molecules, each one with four $\mathrm{Cl}$ atoms. At first glance, seven peaks are observed (including the shoulder that is clearly visible on the peak at ca. $37.6 \mathrm{MHz}$ ), but the largest peak at ca. 37.6 $\mathrm{MHz}$ actually comprises two peaks separated by approximately $10 \mathrm{kHz}$. For phase $\gamma$, the number of resonant ${ }^{35} \mathrm{Cl}$ lines is also eight (Figure 2), which shows up that for this phase the number of the molecules in the asymmetric unit, $Z^{\prime}$, is also two. 


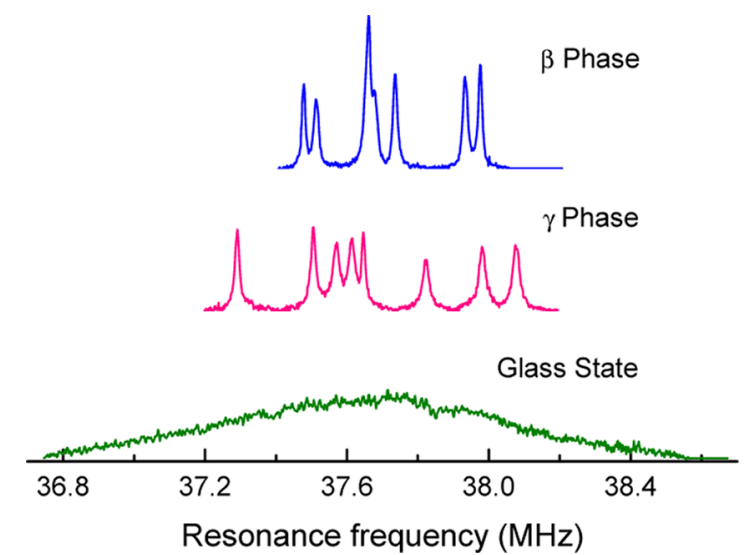

Figure $2 .{ }^{35} \mathrm{Cl} \mathrm{NQR}$ spectra at $79 \mathrm{~K}$ for phases $\beta$ and $\gamma$ as well as for the glass obtained after quench of the liquid state.

The X Cell software within the module Powder Indexing of Materials Studio ${ }^{36,37}$ was applied to the $\mathrm{X}$ ray and neutron diffraction patterns obtained at 150 and $3.5 \mathrm{~K}$, respectively, for indexing purposes. Both resulted into a monoclinic lattice with similar parameters. The systematic absences were compatible with the space group $P 2_{1} / c$, and $Z=8$ was tentatively assigned according to a reasonable density. This implies the existence of two molecules in the asymmetric unit, in agreement with the NQR results. According to the structure of the $\beta$ phase, ${ }^{16}$ it was clearly seen that the neutron measurements for phase $\beta$ displayed strong preferred orientations. Thus, the structure of phase $\gamma$ was solved from $\mathrm{X}$ ray data.

A Pawley refinement was first carried out using the initial unit cell parameters in space group $P 2_{1} / c$. The unit cell parameters, zero point shift, background, peak profile (pseu do Voigt), and peak asymmetry parameters were refined. Because of the similarity between both $\beta$ and $\gamma$ phases, gauche conformers were built up as rigid body molecules by means of the software Forcite from Materials Studio package together with the Dreiding forcefield. ${ }^{36}$ The constructed gauche molecules were then placed as a rigid body in two general positions within the unit cell, and the module Powder Solve was used to solve the structure. Rietveld ${ }^{38}$ and energy minimization were combined one after another successively. In the final Rietveld refinement, the position and orientation of the molecule were refined with the rigid body constraint and with a single overall isotropic displacement parameter. All the profile parameters referred to above were also refined, and the preferred orientation was fitted using the Rietveld Toraya function. ${ }^{39}$ The calculated profile according to the Rietveld refinement is shown in Figure 3 together with the experimental pattern, the differences between calculated and experimental and the Bragg reflections. Parameters of the final refinement are compiled in Table 1, while the atomic coordinates of the two gauche conformers in the asymmetric unit are gathered in Table 2.

Pawley refinement was applied to the $\mathrm{X}$ ray patterns obtained at each temperature, and the lattice parameter variation with the temperature and, indeed, the volume, were determined (see Figure 4).

As far as the stable phase $\beta$ is concerned, $\mathrm{X}$ ray measure ments were also undertaken down to $100 \mathrm{~K}$ to the melting temperature every $20 \mathrm{~K}$. The patterns were fitted according to the structure reported by Bujak et al. ${ }^{16}$ Figure 4 plots the

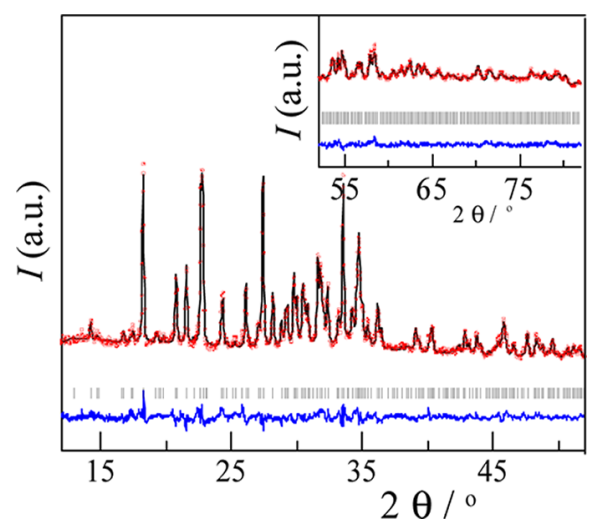

Figure 3. Experimental (red circles) and calculated (black line) X ray diffraction patterns along with the difference profile (blue line) and Bragg reflections (vertical sticks) for the final Rietveld refinement of $P 2_{1} / c$ monoclinic phase $\gamma$ of $1122 \mathrm{TCE}$ at $150 \mathrm{~K}$.

Table 1. Results from the Rietveld Refinement of the Low Temperature Metastable Phase $\gamma$ of $\mathrm{Cl}_{2} \mathrm{HC}-\mathrm{CHCl}_{2}$

\begin{tabular}{|c|c|}
\hline chemical formula & $\mathrm{Cl}_{2} \mathrm{HC} \quad \mathrm{CHCl}_{2}$ \\
\hline $\mathrm{M} / \mathrm{g} \mathrm{mol}^{-1}$ & 167.849 \\
\hline $2 \theta$ angular range & $1290^{\circ}$ \\
\hline space group & $P 2_{1} / c$ \\
\hline$a / \AA$ & $8.9376(20)$ \\
\hline$b / \AA ̊$ & $10.5525(24)$ \\
\hline$c / \AA ̊$ & $12.3822(28)$ \\
\hline$\beta /^{\circ}$ & $90.601(11)$ \\
\hline$V / Z / \AA^{3}$ & $145.97(4)$ \\
\hline$Z ; Z^{\prime}$ & $8 ; 2$ \\
\hline temperature & $150 \mathrm{~K}$ \\
\hline$D_{x} / \mathrm{g} \mathrm{cm}^{-3}$ & $1.909(2)$ \\
\hline radiation type, $\lambda$ & $\left(\mathrm{Cu} \quad \mathrm{K} \alpha_{1}\right), 1.54056 \AA$ \\
\hline \multicolumn{2}{|l|}{ profile parameters } \\
\hline $\mathrm{Na}$ & $0.644(16)$ \\
\hline \multirow[t]{2}{*}{ asymmetry parameters } & $H=0.0170(7)$ \\
\hline & $S=0.0171(8)$ \\
\hline zero shift ${ }^{\circ}$ & $0.0009(22)$ \\
\hline \multicolumn{2}{|l|}{ reliability parameters } \\
\hline$R_{\text {wp }}$ & $5.17 \%$ \\
\hline$R_{\mathrm{p}}$ & $4.04 \%$ \\
\hline \multicolumn{2}{|l|}{ peak width parameters } \\
\hline$U$ & $0.230(30)$ \\
\hline$V$ & $0.028(18)$ \\
\hline$W$ & $0.015(3)$ \\
\hline overall isotropic temperature factor, $U / \AA^{2}$ & $0.0046(5)$ \\
\hline \multicolumn{2}{|c|}{ preferred orientation (Rietveld-Toraya function) } \\
\hline$a^{*}$ & $0.051(12)$ \\
\hline$b^{*}$ & $0.656(7)$ \\
\hline$c^{*}$ & $0.753(6)$ \\
\hline G2 & $1.89(10)$ \\
\hline G1 & $0.391(9)$ \\
\hline
\end{tabular}

volume occupied by a molecule for the stable $\beta$ and metastable $\gamma$ phases.

Several grams of deuterated 1122TCE were submitted to a fast cooling till $3.5 \mathrm{~K}$ into the high resolution powder diffractometer SPODI. Because of the aforementioned problems of preferred orientation of the polycrystalline sample, the pattern at $3.5 \mathrm{~K}$ could not be used for a structural refinement, but pattern matching fits confirm that the so obtained phase is the same than that obtained by fast cooling 
Table 2. Fractional Coordinates for the Two Independent Molecules of the Low Temperature Metastable Phase $\gamma$ of $\mathrm{Cl}_{2} \mathrm{HC}-\mathrm{CHCl}_{2}$

\begin{tabular}{cccc} 
atom & $X$ & $Y$ & $Z$ \\
$\mathrm{C}(1)$ & $0.2856(6)$ & $0.1317(5)$ & $0.3759(4)$ \\
$\mathrm{C}(2)$ & $0.2992(6)$ & $0.0684(5)$ & $0.2637(4)$ \\
$\mathrm{H}(1)$ & $0.2109(6)$ & $0.2134(5)$ & $0.3698(5)$ \\
$\mathrm{H}(2)$ & $0.1897(6)$ & $0.0357(5)$ & $0.2372(5)$ \\
$\mathrm{Cl}(1)$ & $0.2073(8)$ & $0.0279(6)$ & $0.4711(5)$ \\
$\mathrm{Cl}(2)$ & $0.4589(7)$ & $0.1851(5)$ & $0.4280(4)$ \\
$\mathrm{Cl}(3)$ & $0.3630(8)$ & $0.1770(7)$ & $0.1672(4)$ \\
$\mathrm{Cl}(4)$ & $0.4194(6)$ & $0.0636(5)$ & $0.2621(5)$ \\
$\mathrm{C}(11)$ & $0.8041(6)$ & $0.1539(5)$ & $0.1188(4)$ \\
$\mathrm{C}(12)$ & $0.7950(6)$ & $0.0941(5)$ & $0.2329(4)$ \\
$\mathrm{H}(11)$ & $0.7469(6)$ & $0.2453(5)$ & $0.1189(5)$ \\
$\mathrm{H}(12)$ & $0.6787(7)$ & $0.0777(5)$ & $0.2519(5)$ \\
$\mathrm{Cl}(11)$ & $0.7120(8)$ & $0.0590(6)$ & $0.0217(5)$ \\
$\mathrm{Cl}(12)$ & $0.9884(6)$ & $0.1798(5)$ & $0.0750(5)$ \\
$\mathrm{Cl}(13)$ & $0.8658(9)$ & $0.1978(7)$ & $0.3319(4)$ \\
$\mathrm{Cl}(14)$ & $0.8886(6)$ & $0.0520(5)$ & $0.2449(5)$ \\
\hline
\end{tabular}

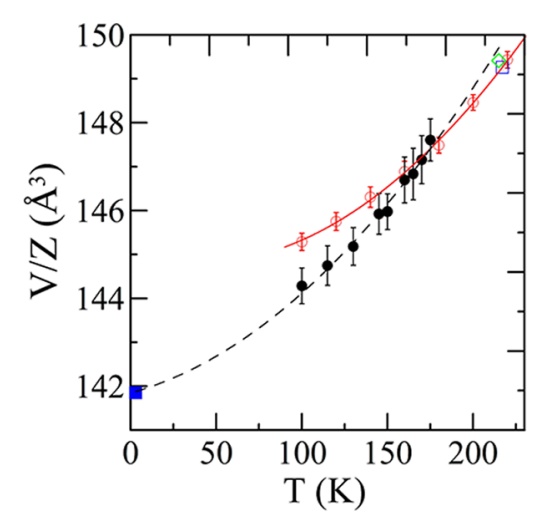

Figure 4. Volume occupied by a molecule as a function of temperature (at normal pressure) for the stable phase $\beta$ (empty symbols) and for the metastable phase $\gamma$ (filled symbols) obtained from $\mathrm{X}$ ray (red circles) and neutron (blue squares) measurements. Green diamond at $215 \mathrm{~K}$ corresponds to the value obtained by Bujak et al. ${ }^{16}$ from single crystal $\mathrm{X}$ ray diffraction.

into liquid nitrogen in the $\mathrm{X}$ ray powder diffraction measure ments. Figure 4 encloses the values obtained for phase $\gamma$ at 3.5 $\mathrm{K}$ and for phase $\beta$ at $217 \mathrm{~K}$ by means of neutron powder diffraction. It can be observed that the metastable phase $\gamma$ transforms to the stable phase $\beta$ at a temperature in which the volume curves cross (ca. $180 \mathrm{~K}$ ), which is close to the temperature determined by calorimetry (ca. $200 \mathrm{~K}$ ). The temperature difference is obviously due to the difference dynamics of the used techniques; while the DSC is a dynamical system in which temperature increases continuously, $\mathrm{X}$ ray measurements (as well as NQR measurements) are done in isothermal conditions, so the metastability has a lower lifetime.

\section{DISCUSSION}

For substances constituted by molecules with different conformers, the crystallization process from the liquid phase, where in general all the conformers are present, generally favors one conformer, that is energetically more favorable. ${ }^{20-26}$ For $1122 \mathrm{TCE}$ the energy difference between trans and gauche conformers is lower than $1 \mathrm{kcal} \mathrm{mol}^{-1},{ }^{20-25}$ which means that ordered structures will be governed mainly by the intermo lecular interactions, due to the subtle role of the molecular conformations. The case of 1122TCE is somehow "excep tional", ${ }^{16,17}$ because at high but still moderate pressures, 0.5 $\mathrm{GPa}$, the phase $\alpha$ was found to be disordered in such a way that the $\mathrm{Cl}$ atoms occupy common sites, while the $>\mathrm{HC}-\mathrm{CH}<$ entity shows two different orientations. It must be pointed out that such a disorder does not modify the trans conformation of the molecule. On increasing pressure (at ca. $0.65 \mathrm{GPa}$ ), the occupational disorder disappears and the structure orders into a monoclinic $P 2_{1} / c$ structure with $Z^{\prime}=0.5$ formed by trans $\left(C_{2 h}\right.$ symmetry) conformers. Furthermore, when comparing the normal pressure stable $\beta$ and metastable $\gamma$ phases, it can be seen at a glance that in both cases molecules are packed in columns along the $c$ axis. In the $\gamma$ phase, the two independent molecules are approximately related by a noncrystallographic $2_{1}$ axis running along $c$, whereas in the $\beta$ phase they are related by a nonperiodic translation of about $(0, b / 4, c / 2)$.

A quick look into the closest $\mathrm{Cl} \cdots \mathrm{Cl}$ contacts for the different polymorphs shows the differences about the interactions between phases. Table 3 gathers the closest intermolecular halogen contacts (shorter than the sum of the van der Waals radii of $\mathrm{Cl}$ ) for all the phases. It can be seen that the high pressure phase $\alpha$ displays the longest halogen contacts, in spite of the highest packing of this phase (lowest volume), according to the values given by Bujak et al. ${ }^{16}$ A noticeable difference can be found between the contacts when comparing the stable $\beta$ and the metastable $\gamma$ normal pressure phases. For the latter, Figure 5 shows the refined structure together with the shortest intermolecular halogen contacts. It can be seen that the shortest contacts appear between molecules with different gauche conformations related by the glide plane as $\mathrm{Cl}(3) \cdots \mathrm{Cl}(2)$, $3.417 \AA$ and $\mathrm{Cl}(13) \cdots \mathrm{Cl}(12), 3.445 \AA$. Nevertheless, some distances between the same conformer are very close to the previous one, as $\mathrm{Cl}(4) \cdots \mathrm{Cl}(3), 3.465 \AA$. The most striking difference between the phases, making the intermolecular interactions different concerns the angles $\mathrm{C}-\mathrm{Cl} \cdots \mathrm{Cl}\left(\theta_{1}\right)$ and $\mathrm{Cl} \cdots \mathrm{C}-\mathrm{Cl}\left(\theta_{2}\right)$, as it has deeply studied (see ref 40$)$. Although there are different factors accounting for the energy interaction (as the effects of attaching different electronegative atoms to the same carbon atom or even the hybridization of the carbon atom), it has been shown that, for $\mathrm{Cl}$ atoms attached to $\mathrm{sp}^{3}$ hybridized $\mathrm{C}$ atoms, as in the present case, for angles $\mathrm{C}-\mathrm{Cl} \cdots \mathrm{Cl}$ and $\mathrm{Cl} \cdots \mathrm{C}-\mathrm{Cl}$ around $140-160^{\circ}\left(\theta_{1} \approx \theta_{2}\right.$, called type I contact) there is an energy minimum (attraction) in the interaction electrostatic potential calculated on the basis on a purely electrostatic model. An additional energy minimum appears when $\theta_{1} \approx 180^{\circ}$ and $\theta_{2} \approx 90^{\circ}$ (called type II contact). Some type I and type II contacts appear in phase $\beta$. As pointed out by Bujak et al., ${ }^{16}$ halogen $\cdots$ halogen interactions are attractive and directional in phase $\beta,^{39}$ while angles in the high pressure phase $\alpha$ appear to be clearly distorted (see Table 3 ). As for the new phase, the number of $\mathrm{Cl} \cdots \mathrm{Cl}$ contacts with distances shorter than the sum of the van der Waals radii increases noticeably (values are gathered in Table 3). In addition, four of the five shorter contacts correspond to type II contacts with $\theta_{1} \approx 164^{\circ}$ and $\theta_{2} \approx 90^{\circ}$, which means that $\mathrm{Cl} \cdots \mathrm{Cl}$ interactions in phase $\gamma$ are also attractive and directional like in phase $\beta$. The electrostatic model in the case with $\theta_{2} \approx 90^{\circ}$ was not developed in detail because type II interactions are strongly affected by effects as steric, electronic, other intermolecular interactions, making difficult computational calculations, although "the stability of this geometry is expected based on the electrostatic model". ${ }^{40}$ The thermodynamic experimental 
Table 3. Intermolecular Contacts (in $\AA$ for Distances and in ${ }^{\circ}$ for Angles) for the $\alpha, \beta$, and $\gamma \operatorname{Polymorphs}$ of $\mathrm{Cl}_{2} \mathrm{HC}-\mathrm{CHCl}_{2}{ }^{a}$

\begin{tabular}{|c|c|c|c|c|c|c|}
\hline \multicolumn{7}{|c|}{ phase } \\
\hline \multicolumn{3}{|c|}{$\beta 0.1 \mathrm{MPa}, 215 \mathrm{~K}$} & \multicolumn{2}{|c|}{$\gamma 0.1 \mathrm{MPa}, 150 \mathrm{~K}$} & \multicolumn{2}{|c|}{$\alpha 0.65 \mathrm{GPa}, 295 \mathrm{~K}$} \\
\hline $\mathrm{Cl}(1)$ & $\mathrm{Cl}(2)^{b}$ & $3.434(2)$ & $\mathrm{Cl}(3) \quad \mathrm{Cl}(2)^{d}$ & $3.417(8)$ & $\mathrm{Cl}(1) \quad \mathrm{Cl}(1)^{i}$ & $3.453(3)$ \\
\hline $\mathrm{Cl}(1)$ & $\mathrm{Cl}(2)^{b} \mathrm{C}(1)^{b}$ & 174 & $\mathrm{C}(2) \mathrm{Cl}(3) \quad \mathrm{Cl}(2)^{d}$ & 162.6 & $\mathrm{Cl}(1) \quad \mathrm{Cl}(1)^{i} \mathrm{C}(1)^{i}$ & 123 \\
\hline$C(1)$ & $\mathrm{Cl}(1) \mathrm{Cl}(2)^{b}$ & 91 & $\mathrm{Cl}(3) \quad \mathrm{Cl}(2)^{d} \mathrm{C}(1)^{d}$ & 103.1 & $\mathrm{C}(1) \mathrm{Cl}(1) \quad \mathrm{Cl}(1)^{i}$ & 123 \\
\hline $\mathrm{Cl}(3)$ & $\mathrm{Cl}(6)^{c}$ & $3.437(1)$ & $\mathrm{Cl}(13) \mathrm{Cl}(12)^{e}$ & $3.445(8)$ & $\mathrm{Cl}(1) \quad \mathrm{Cl}(2)^{j}$ & $3.453(3)$ \\
\hline $\mathrm{Cl}(3)$ & $\mathrm{Cl}(6)^{c} \mathrm{C}(3)^{c}$ & 131 & $\mathrm{C}(12) \mathrm{Cl}(13) \mathrm{Cl}(12)^{e}$ & 162.3 & $\mathrm{Cl}(1) \quad \mathrm{Cl}(2)^{j} \mathrm{C}(1)^{j}$ & 152 \\
\hline $\mathrm{C}(2)$ & $\mathrm{Cl}(3) \mathrm{Cl}(6)^{c}$ & 144 & $\mathrm{Cl}(13) \mathrm{Cl}(12)^{e} \mathrm{C}(11)^{e}$ & 92.1 & $\mathrm{C}(1) \quad \mathrm{Cl}(1) \quad \mathrm{Cl}(2)^{j}$ & 111 \\
\hline & & & $\mathrm{Cl}(4) \quad \mathrm{Cl}(3)^{g}$ & $3.465(9)$ & & \\
\hline & & & $\mathrm{C}(2) \mathrm{Cl}(4) \quad \mathrm{Cl}(3)^{g}$ & 164.6 & & \\
\hline & & & $\mathrm{Cl}(4) \quad \mathrm{Cl}(3)^{g} \quad \mathrm{C}(2)^{g}$ & 122 & & \\
\hline & & & $\mathrm{Cl}(1) \mathrm{Cl}(13)^{f}$ & $3.476(9)$ & & \\
\hline & & & $\mathrm{C}(1) \mathrm{Cl}(1) \quad \mathrm{Cl}(13)^{f}$ & 167.3 & & \\
\hline & & & $\mathrm{Cl}(1) \quad \mathrm{Cl}(13)^{f} \quad \mathrm{C}(12)^{f}$ & 89.6 & & \\
\hline & & & $\mathrm{Cl}(11) \quad \mathrm{Cl}(3)^{h}$ & $3.477(9)$ & & \\
\hline & & & $\mathrm{C}(11) \mathrm{Cl}(11) \mathrm{Cl}(3)^{h}$ & 162.1 & & \\
\hline & & & $\mathrm{Cl}(11) \quad \mathrm{Cl}(3)^{h} \mathrm{C}(2)^{h}$ & 85.9 & & \\
\hline
\end{tabular}

${ }^{a}$ Values for phases $\alpha$ and $\beta$ were taken from Bujak et al. ${ }^{16}{ }^{b}$ Symmetry codes: $x-1 / 2,-y+1 / 2,-z \cdot{ }^{c} x+1 / 2,-y+1 / 2,-z+1 .{ }^{d} x,-y+1 / 2, z-1 /$ 2. ${ }^{e} x,-y+1 / 2, z+1 / 2 .{ }^{f}-x+1,-y,-z+1 .^{g}-x+1, y-1 / 2,-z+1 / 2 .{ }^{h}-x+1,-y,-z{ }^{i}-x+2,-y,-z+2 .{ }^{j}-x+1, y-1 / 2,-z+3 / 2$.

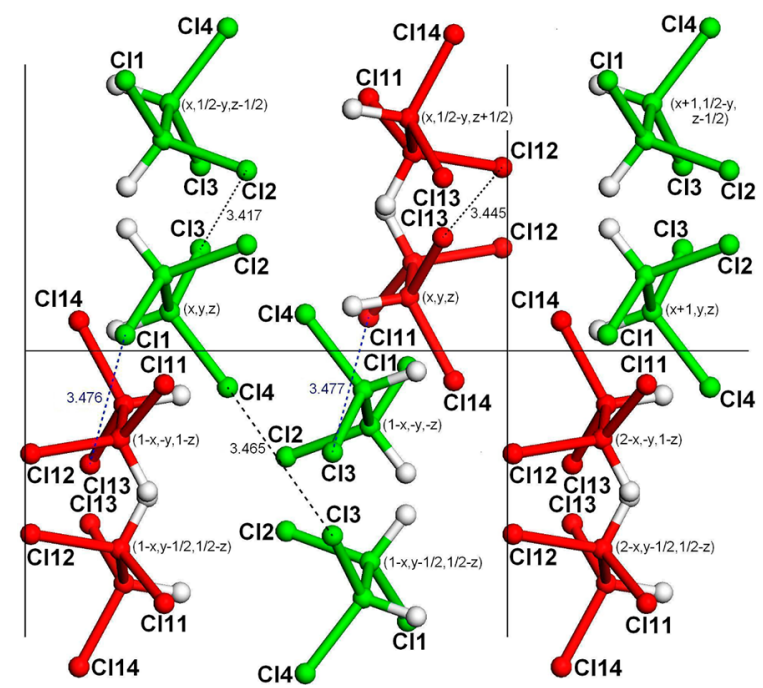

Figure 5. Refined structure of the metastable phase $\gamma$ of $\mathrm{Cl}_{2} \mathrm{HC}-$ $\mathrm{CHCl}_{2}$ determined from $\mathrm{X}$ ray diffraction at $150 \mathrm{~K}$, viewed down the crystallographic $c$ axis. Dotted lines denote $\mathrm{Cl} \cdots \mathrm{Cl}$ contacts, some of them listed in Table 3. Red and green molecules denote the two independent molecules of the asymmetric unit. $\mathrm{H}$ atom is drawn in white.

data offers us the opportunity to balance the intermolecular interactions due to the existence of type II Cl $\cdots \mathrm{Cl}$ contacts. The irreversible transition from phase $\gamma$ to phase $\beta$ is exothermal $\left(\Delta H^{\gamma \rightarrow \beta}=-2.30 \mathrm{~kJ} \mathrm{~mol}^{-1}\right)$, which means that phase $\beta$ has a lower energy than phase $\gamma$. Thus, although the intermolecular interactions on the former are also attractive and directional, the presence of a noticeable number of Type II contacts is not enough to strength the overall interactions in phase $\gamma$.

The temperature and pressure stability domain of the new phase $\gamma$ is unknown. Nevertheless, some speculations can be ventured. The fact that phase $\gamma$ is denser than phase $\beta$ (see Figure 4) means that the $\gamma \rightarrow \beta$ phase transition involves a positive volume change, which together with the measured negative value of the enthalpy change, $\Delta H^{\gamma \rightarrow \beta}$, consistently gives rise to a negative $\mathrm{d} p / \mathrm{d} T$ slope of the two phase equilibrium $\gamma-\beta$ in the pressure-temperature phase diagram, according to the Clapeyron equation. The fact that phase $\alpha$ is found by isothermal compression of phase $\beta$, would indicate that phase $\alpha$ is a high pressure stable phase. The two phase coexistence equilibrium $\gamma-\beta$, with a negative slope can also appear as a stable coexistence equilibrium (and thus, a stability region for the $\gamma$ phase could exist), but certainly getting the phase $\gamma$ by compression of phase $\beta$ would be difficult at least that such a compression took place at low temperature and, moreover, the lower the temperature the higher the pressure. Similar phase behavior was found for the two polymorphs of progesterone. ${ }^{11}$

To end with, it should be pointed out the pioneering work of Kagarise $^{24}$ already suggesting the possible existence of different polymorphs at normal pressure. Kagarise tried out different cooling procedures in order to prepare a crystal with trans conformers of $1122 \mathrm{TCE}$, among them "rapid cooling with liquid nitrogen". Although the efforts to get the "trans crystal" were unsuccessful, he found "indications that the gauche crystal can exist in several polymorphic phases, since slight differences in frequency $\left(<10 \mathrm{~cm}^{-1}\right)$ and relative intensity have been observed between samples prepared in different fashions." These results were later confirmed by Takeda and Gutowsky. ${ }^{25}$ Moreover, in 1965, Brasch ${ }^{19}$ not only was able to build up a high pressure single crystal formed exclusively with trans conformers, in agreement with the recent results about the structure of Bujak et al., ${ }^{16}$ but also to find differences in normal pressure polymorphs formed by "different gauche rotamers". Now, all these pioneering results find a perfect physical coherence.

\section{CONCLUSIONS}

A new polymorph of $1,1,2,2$ tetrachloroethane $\left(\mathrm{Cl}_{2} \mathrm{HC}-\right.$ $\mathrm{CHCl}_{2}$ ), phase $\gamma$, has been found. It has been obtained by recrystallization upon heating the glass obtained from the quench of the liquid. The irreversible transition upon heating phase $\gamma$ to phase $\beta$ indicates that the new polymorph is metastable at normal pressure.

The structure of phase $\gamma$ is found to be monoclinic, space group $P 2_{1} / c$, with eight molecules in the unit cell and two molecules in the asymmetric unit. Although phase $\gamma$ displays the same space group of that of the high pressure stable phase $\alpha$, 
the former is known to be formed only by molecules with trans conformation and two molecules per unit lattice and a half molecule in the asymmetric unit. While the normal pressure stable phase $\beta$ is formed by molecules exhibiting the same gauche conformer, the new polymorph involves the two gauche conformers, both being present in the asymmetric unit. Phase $\gamma$ displays short $\mathrm{Cl} \cdots \mathrm{Cl}$ contacts, ever shorter than for the high pressure phase $\alpha$. Many of these halogen $\cdots$ halogen short contacts belong to the type II according to the description of ref 40 , which means that interactions are attractive and directional. The simple fact that the irreversible $\gamma \rightarrow \beta$ phase transition appears to be an exothermal process on heating means that the overall intermolecular interactions in phase $\gamma$ are higher than in phase $\beta$.

\section{AUTHOR INFORMATION}

\section{Corresponding Author}

*E mail: josep.lluis.tamarit@upc.edu.

Notes

The authors declare no competing financial interest.

\section{ACKNOWLEDGMENTS}

This work was partially supported by the Spanish Ministry of Science and Innovation (Grant FIS2011 24439), the Catalan Government (Grant 2009SGR 1251), and by CONICET and SECYT UNC of Argentina.

\section{REFERENCES}

(1) Brittain, H. G. J. Pharm. Sci. 2012, 101, 464.

(2) Rogers, R. D. Cryst. Growth Des. 2004, 4, 1085

(3) Boldyreva, E. Cryst. Growth Des. 2007, 7, 1662.

(4) McMillan, P. F. Chem. Soc. Rev. 2006, 35, 855.

(5) Barsky, I.; Bernstein, J.; Stephens, P. W.; Stone, K. H.; Cheung, E.; Hickey, M. B.; Henck, J. O. Cryst. Growth Des. 2008, 8, 63.

(6) Bernstein, J.; Dunitz, J. D.; Gavezzotti, A. Cryst. Growth Des. 2008, 8, 2011.

(7) Rafilovich, M.; Bernstein, J. J. Am. Chem. Soc. 2006, 128, 12185.

(8) Neumann, M. A.; Perrin, M. A. CrystEngComm 2009, 11, 2475.

(9) Barrio, M.; Maccaroni, E.; Rietveld, I. B.; Malpezzi, L.; Masciocchi, N.; Céolin, R.; Tamarit, J. Ll. J. Pharm. Sci. 2012, 101, 1073.

(10) Rietveld, I. B.; Barrio, M.; Tamarit, J.Li.; Nicolaï, B.; van de Streek, J.; Mahé, N.; Ceolin, R.; Do., B. J. Pharm. Sci. 2011, 100, 4774.

(11) Barrio, M.; Espeau, P.; Tamarit, J. Ll.; Perrin, M. A.; Veglio, N.; Céolin, R. J. Pharm. Sci. 2009, 98, 1657.

(12) Parat, B.; Pardo, L. C.; Barrio, M.; Tamarit, J. Ll.; Negrier, Ph.; Salud, J.; López, D. O.; Mondieig, D. Chem. Mater. 2005, 17, 3359.

(13) Negrier, Ph.; Barrio, M.; Tamarit, J. Ll.; Pardo, L. C.; Mondieig, D. Cryst. Growth Des. 2012, 12, 1513.

(14) Mahé, N.; Perrin, M. A.; Barrio, M.; Nicolaï, B.; Rietveld, I. B.; Tamarit, J. Ll.; Céolin, R. J. Pharm. Sci. 2011, 100, 2258.

(15) Ibberson, R. M.; Telling, M. T. F.; Parsons, S. Cryst. Growth Des. 2008, 8, 512.

(16) Bujak, M.; Bläser, D.; Katrusiak, A.; Boese, R. Chem. Commun.

2011, 47, 8769 .

(17) Bujak, M.; Katrusiak, A. Z. Kristallogr. 2004, 219, 669.

(18) Kolesov, V. P. Thermochim. Acta 1995, 266, 129.
(19) Brasch, J. W. J. Chem. Phys. 1965, 43, 3473.

(20) Naito, K.; Nakagawa, K.; Kuratani, K.; Ichishima, I.; Mizushima, S. J. Chem. Phys. 1955, 23, 1907.

(21) Zietlow, J. P.; Cleveland, F. F.; Meister, A. G. J. Chem. Phys. 1956, 24, 142.

(22) Kagarise, R. E.; Rank, D. H. Trans. Faraday Soc. 1952, 48, 394.

(23) Plyler, E. K. J. Chem. Phys. 1949, 17, 218.

(24) Kagarise, R. E. J. Chem. Phys. 1956, 24, 300.

(25) Takeda, M.; Gutowsky, H. S. J. Chem. Phys. 1957, 26, 577.

(26) Rovira Esteva, M.; Murugan, N. A.; Pardo, L. C.; Busch, S.; Tamarit, J. Ll.; Pothoczki, Sz.; Cuello, G. J.; Bermejo, F. J. Phys. Rev. B 2011, 84, 064202.

(27) Durig, J. R.; Liu, J.; Little, T. S.; Kalasinsky, V. F. J. Phys. Chem. 1992, 96, 8224

(28) Abraham, R. J.; Parry, K. J. Chem. Soc. B 1970, 539.

(29) Wolfe, S. Acc. Chem. Res. 1972, 5, 102.

(30) Bingham, R. C. J. Am. Chem. Soc. 1976, 98, 535.

(31) Ballon, J.; Comparat, V.; Pouxe, J. Nucl. Instrum. Methods 1983, 217, 213.

(32) Evain, M.; Deniard, P.; Jouanneaux, A.; Brec, R. J. Appl. Crystallogr. 1993, 26, 563.

(33) Gilles, R.; Artus, G.; Saroun, J.; Boysen, H.; Fuess, H. Physica B 2000, 276, 87.

(34) Bussandri, A. P.; Zuriaga, M. J. J. Magn. Reson. 1998, 131, 224.

(35) Domalski, E. S.; Hearing, E. D. J. Phys. Chem. Ref. Data 1996, $25,1$.

(36) MS Modeling (Material Studio), version 4.1; Accelrys: San Diego, CA; http://www.accelrys.com/mstudio/ms modeling.

(37) Neumann, M. A. J. Appl. Crystallogr. 2003, 36, 356.

(38) Rietveld, H. M. J. Appl. Crystallogr. 1969, 2, 65.

(39) Toraya, H.; Marumo, F. Mineral. J. 1981, 10, 211.

(40) Awwadi, F. F.; Willett, R. D.; Peterson, K. A.; Twamley, B. Chem.-Eur. J. 2006, 12, 8952. 